\title{
Correspondence
}

Sir: Robertson \& Dean (1997) provide welcome clarification of what is expected of consultants in mandatory weekly one-hour sessions of supervision of trainees. I see my trainees, not always in the plural, but practically every day, see patients in their presence, read their notes, countersign their case summaries, monitor their emergency work, hear their case presentations, chat them up about psychiatry and generally worry about them and what they think of me - and much more. But this is not enough. I must closet myself with each of them for an hour each week. What happens in these sessions? I used to fantasise that the parties spored anaerobically. I now realise my error: they are in fact nurturing each other. The next essential step is independent counselling for trainees, especially those who cannot decide whether they should bring a toothbrush or a pack of cards to supervision sessions. Inevitably, future developments will include counselling for consultants (voluntary at first), particularly those manifesting symptoms of chronic supervision abuse (CSA). A Wildean appreciation of this scenario might be the pursuit of the unsupervisable by the unmentorable, devised by the untaught. The evidence-based framework for all this is clear: consultants uncomfortable with teaching can be made to teach well by threatening to withdraw training scheme approval if they fail to comply. One can, after all, bring a horse to water and make him drink, provided only that one flogs him enough. Trainees who avoid what they foolishly perceive as situations of unhealthy conceptual uncertainty can be induced not only to participate, but also hugely to enjoy the experience. Dim-witted colleagues deluded that protected time for consultants is of any relevance will have their say, but their day is done: the new millennium will find them wandering the psychiatric desert, mouthing phenomenological obscenities and mumbling incoherently about the value of spending time with patients.

For all these things an immense debt of gratitude is due to those guardians of postgraduate training in psychiatry who now alone are capable of tackling the final question:quis custodiet ipsos custodes?

Robertson, J. R. \& Dean, A. (1997) General professional
training: consultant supervision of trainees. Advances in
Psychiatric Treatment, 3, 347-351.

T. J. Fahy Department of Psychiatry, Clinical Science Institute, University College Galway

\section{Cycles of Abuse: Domestic Violence and Mental Health} Two-day conference on Wednesday 24 and Thursday 25 November 1998 in London

The aim is to draw in all psychiatrists and mental health practitioners to explore the mental health perspectives of domestic violence - a subject that impacts on the work of all psychiatrists. Speakers and workshop leaders will be practitioners and policy-makers drawn from psychiatry, psychology, nursing, the law, the voluntary sector and general medicine. Following the format of previous Cycles of Abuse Conferences, inter-Faculty and multi-agency participation will lead to informed debate and increased knowledge. The conference will close with contributions from Chairs of Faculties.

Topics include:

- Domestic violence as a public health issue

- Domestic violence and the law

- Assessment and treatment of victims and perpetrators

- Domestic violence and special groups - elderly, learning disability, children and adolescents

- Impact of substance misuse

There will be a choice of eight workshops on both days covering assessment and treatment approaches for victims and perpetrators of whatever age. Further details from Joanna Carroll, CPD Unit, The Royal College of Psychiatrists (Tel: 0171235 2351, ext. 108; fax: 0171259 6507; e-mail: jcarroll@rcpsych.ac.uk) 